$\mathrm{XX}$ Міжнародний симпозіум «Методи дискретних особливостей в задачах математичної фізики/Discrete Singularities Methods in Mathematical Physics», МДОЗМФ/DSMMPh-2021

УДК 533

MSC 76J20

\title{
Modeling of gas-dynamic processes in the elements of impulse ejector
}

\author{
G.O. Voropaiev, Ia.V. Zagumennyi, N.V. Rozumnyuk \\ Institute of Hydromechanics of the NAS of Ukraine, Kyiv, Ukraine \\ E-mail:voropaiev.gena@gmail.com,zagumennyi@gmail.com
}

\begin{abstract}
The paper presents the numerical results on gas-dynamic processes in various elements of the impulse ejector, including pre-chamber, supersonic nozzle and mixing chamber, to determine optimal geometric parameters providing the given flow rate characteristics. At an extra-high pressure of the ejecting gas ( $>100$ bar) it is impossible to create a nozzle design with continuously changing cross-sectional area and limited nozzle length. So, it is necessary to place a pre-chamber between the gas generator and the ejector nozzle for throttling full gas pressure. In order to optimize the pre-chamber parameters in the ejector with discrete holes of the gas generator and the operating pressure in the range of $400 \div 1000$ bar, a series of calculations were performed to determine the pre-chamber parameters, ensuring stable operation of the supersonic annular nozzle at the high pressure of $35 \div 45$ bar and the flow rate of $0.5 \div 0.6 \mathrm{~kg} / \mathrm{s}$. 3D numerical simulation of the gas flow into the pre-chamber through the gas generator holes shows the degree of the flow pattern non-uniformity in the pre-chamber at the ejector nozzle inlet is quite low. This justifies the numerical simulation of gas flow in the ejector in axisymmetric formulation and allows restricting the number of the gas generator holes without inducing significant nonuniformity in the azimuthal direction.
\end{abstract}

Key words: impulse ejector, supersonic jet, gas flow rate, numerical simulation.

\section{Моделювання газодинамічних процесів в елементах імпульсного ежектора \\ Г.О. Воропаєв, Я.В. Загуменний, Н.В. Розумнюк Інститут гідромеханіки НАН України, Київ, Україна \\ E-mail:voropaiev.gena@gmail.com,zagumennyi@gmail.com}

В роботі представлено результати чисельного моделювання газодинамічних процесів в форкамері імпульсного надзвукового ежектора 3 метою визначення оптимальних геометричних параметрів, що забезпечують задані витратні характеристики ежектора. При надвисокому тиску ежектуючого газу (>100 атм) неможливо створити розрахункове сопло з неперервно змінюваною площею перерізу і обмеженою довжиною, тому між газогенератором та соплом ежектора необхідно розмістити форкамеру для дроселювання повного тиску газогенератора. 3 метою оптимізації параметрів форкамери ежектора 3 дискретними отворами газогенератора і робочим тиском в діапазоні 400 $\div 1000$ атм було проведено серію розрахунків з визначення параметрів форкамери, що забезпечують стабільну роботу надзвукового кільцевого сопла при вхідному тиску $35 \div 45$ атм і масовій витраті $0.5 \div 0.6$ кг/с. Тривимірне чисельне моделювання точкового витікання газу з газогенератора у форкамеру і далі у кільцеве сопло показало, що ступінь нерівномірності картини течії у форкамері на вході до сопла ежектора є досить низькою, що обгрунтовує проведення чисельного моделювання течії в надзвуковому кільцевому соплі та камері змішування ежектора в осесиметричній постановці та дозволяє обмежити кількість циліндричних отворів газогенератора без внесення суттєвої неоднорідності у розподіли характеристик по азимутальній координаті.

Ключові слова: ежектор, надзвуковий струмінь, масова витрата, чисельне моделювання.

(С) Воропаєв Г.О., Загуменний Я.В., Розумнюк Н.В., 2021 


\section{1. Ветуп}

Актуальність досліджень газодинамічних процесів в імпульсних ежекторах обумовлена широким спектром застосування обладнання та пристроїв, де використовуються ефекти взаємодії надзвукових струменів 3 дозвуковим навколишнім середовищем поблизу твердих границь та всередині обмежених областей різної геометричної форми. Однією 3 найбільш значимих особливостей ежекторів даного типу є можливість їх використання в системах інноваційних подушок безпеки автомобілів, які, на відміну від традиційних, використовують повітря 3 салону для наповнення $0.5 \div 0.75$ об'єму подушки.

При формуванні імпульсних надзвукових струменів та зміні їх напрямку в часі і просторі в обмежених об'ємах утворюються складна система стрибків згущення та зон розрідження, виникають зони стрімкої зміни величин газодинамічних параметрів потоку, відриви турбулентних примежових шарів на стінках камери змішування $[1,2]$. При певному співвідношенні геометричних та фізичних параметрів в результаті взаємодії надзвукового струменя та дозвукового середовища досить великий об'єм нерухомого газу навколо струменя прискорюється та переноситься в напрямку руху надзвукового струменя. Дослідження даних процесів мають значний фундаментальний і практичний інтерес та залишаються актуальними по сьогоднішній день, про що свідчить велика кількість сучасних робіт $з$ даної тематики як експериментальних [3, 4], так і теоретичних, з яких найбільшу перевагу віддається методам чисельного моделювання [5-7].

В даній роботі представлено деякі результати чисельного моделювання газодинамічних процесів в різних елементах імпульсної ежекторної системи, що забезпечують задані витратні характеристики ежектора. Одним із найважливіших завдань у цьому напрямку є визначення оптимальних параметрів форкамери, що має бути розміщена між газогенератором та соплом ежектора, оскільки при надвисокому тиску ежектуючого газу неможливо створити розрахункове сопло неперервно змінюваної площі перерізу і обмеженої довжини.

\section{2. Постановка задачі та метод розрахунку}

Моделювання імпульсної надзвукової течії в ежекторній системі здійснюється на основі розв'язання тривимірної нестаціонарної системи повних рівнянь Рейнольдса без виділення стрибків стискання, що описує рух в'язкого стисливого неізотермічного середовища і замикається за допомогою моделі турбулентності Спаларта-Аллмареса [8] (тестування інших моделей турбулентності не виявило суттєвих переваг) та відповідними граничними умовами [6]. Чисельне моделювання виконано методом скінченного об'єму, який реалізується в обчислювальному пакеті OpenFOAМ з відкритим вихідним кодом [5].

Результуюча система лінійних алгебраїчних рівнянь, що утворюється в результаті дискретизації вихідної системи диференціальних рівнянь, розв'язується з використанням ітераційних методів спряжених градієнтів з наперед встановленою точністю і заданою кількістю внутрішніх та зовнішніх ітерацій процедури PIMPLE для зв'язування полів швидкості і тиску. Для інтерполяції конвективних членів застосовується TVD схема $з$ обмежувачем, що забезпечує мінімальну чисельну дифузію і відсутність осциляції розв'язку. Для дискретизації похідної за часом використовується неявна трьохточкова несиметрична схема другого порядку для забезпечення високої точності розрахунку фізичного процесу в часі. 
XX Міжнародний симпозіум «Методи дискретних особливостей в задачах математичної фізики/Discrete Singularities Methods in Mathematical Physics»,

\section{МДОЗМФ/DSMMPh-2021}

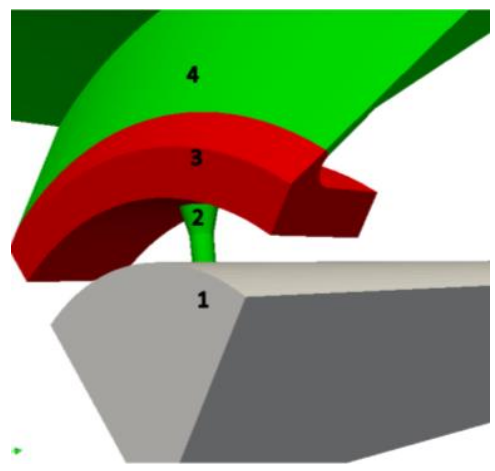

a)

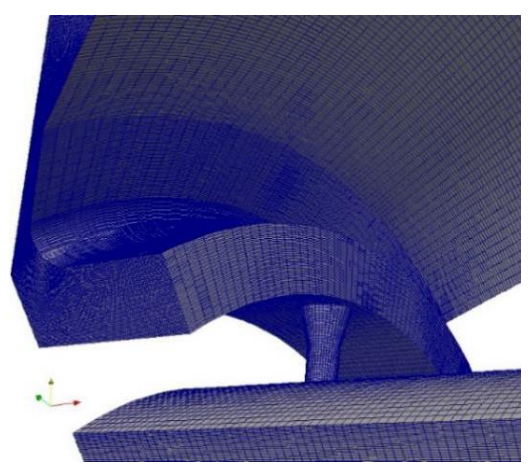

б)

Рис.1. Тривимірна геометрія розрахункового сектору (а) і фрагмент згенерованої тривимірної розрахункової сітки (б). Позначення елементів ежектора: 1 - газогенератор, 2 - циліндричний отвір, 3 - форкамера, 4 - кільцеве сопло.

Обчислення виконуються лише в області одного сектора, який відповідає окремому дискретному отвору з газогенератора, у припущенні повторюваності фізичного процесу в усіх інших розрахункових секторах, що в сукупності складають всю внутрішню частину складових елементів ежектора (Рис.1). Усередині розрахункового сектора будується ортогональна структурована сітка, що згущується у напрямку до стінок ежектора 3 метою адекватного розрахування в'язких ефектів. Забезпечення досить високої розрахункової здатності досліджуваного фізичного процесу в просторі і часі гарантується досить високою загальною роздільною здатністю розрахункової області (до $10^{7}$ розрахункових комірок), при цьому крок за часом контролювався у зв'язці з просторовими масштабами комірок сітки через число Куранта. Розрахунки задач проводилися в паралельному режимі з використанням багатоядерних персональних комп'ютерів і обчислювальних ресурсів кластерних систем.

\section{3. Результати розрахунків}

Формування полів газодинамічних параметрів в форкамері представлено на прикладі камер з безрозмірними об'ємами відносно об'єму газогенератора: $\mathrm{V}_{\mathrm{f}}=0.039 \mathrm{i} \mathrm{V}_{\mathrm{f}}=0.084$ для різних геометричних модифікацій вихідних отворів з газогенератора і при фіксованій площі вихідного кільцевого сопла $з$ форкамери в камеру змішування. Зміна довжини вихідних отворів 3 газогенератора виконувалося при умові збереження положення стінок форкамери, при цьому переміщувалась на відповідну відстань стінка газогенератора за умови фіксації його об'єму. Розрахунки параметрів течії газу в форкамері і соплі ежектора виконано з урахуванням зміни тиску і температури в газогенераторі з моменту досягнення їх максимальних значень $\left(\mathrm{P}_{\max }=800 \mathrm{bar}, \mathrm{T}_{\max }=1200{ }^{\circ} \mathrm{K}\right)$ і подальшого природного спадання при фіксованому діаметрі вихідного отвору $(\mathrm{d}=1.2 \mathrm{mм})$, змінних його довжині $(\mathrm{L}=1 \div 3 \mathrm{Mм}) \mathrm{i}$ куті розкриття дифузорної частини $\left(\alpha=0 \div 35^{\circ}\right)$ циліндричного вихідного отвору 3 газогенератора та двох значень висоти форкамери (H=2.5 мм і $\mathrm{H}=5.0$ мм). При відкритті клапану газогенератора і проходженні ударної хвилі по форкамері в ній фо- 
рмується потік газу, розподіл газодинамічних параметрів якого пропорційний відношенню тиску в газогенераторі і форкамері.

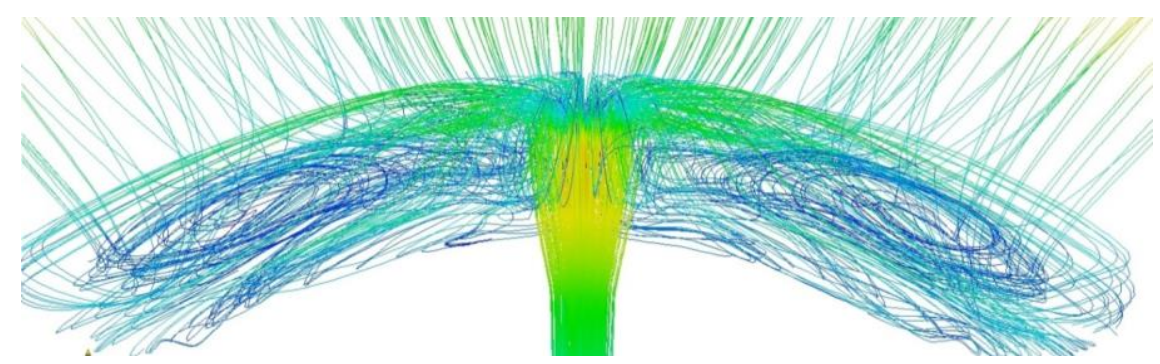

Рис.2. Вихровий рух газу у форкамері.

Тривимірну візуалізацію миттєвої структури течії газу у форкамері з використанням методу простежування траєкторії рідких частинок наведено на Рис.2 для моменту часу $\mathrm{t} \sim 0.1$ мс, коли встановлюється фактично усталена структура течії. Процес іiі формування, що передує даному моменту часу, проходить через ряд послідовних нестаціонарних етапів: формування надзвукового струменя при витіканні газу з газогенератора через циліндричний отвір і його взаємодія 3 протилежною стінкою форкамери ( $\mathrm{t}=0.004 \mathrm{Mc})$; розтікання струменя уздовж контактної стінки $\mathrm{i}$ подальша взаємодія потоку з іншими найближчими стінками форкамери 3 відповідною зміною напрямку руху газу ( $\mathrm{t}=0.004 \div 0.01 \mathrm{mc})$; виникнення пари вихорів, симетрично розташованих відносно центрального осьового перерізу ежектора, що проходить через вісь вихідного отвору з газогенератора ( $\mathrm{t}=0.01 \div 0.02 \mathrm{Mc})$; взаємодія газового потоку з периферійними границями розрахункової області, на яких задані циклічні граничні умови ( $\mathrm{t}>0.02 \mathrm{mc})$. В результаті складної нестаціонарної взаємодії в периферійній області форкамери формуються складні локалізовані вихрові структури, які в процесі еволюції у часі поступово простягаються в аксіальному напрямку і заповнюють об'єм форкамери ( $\mathrm{t} \sim 0.1 \mathrm{mc}$ ).

На Рис.3 представлено розподіли числа Маха і тиску уздовж лінії, що збігається 3 віссю отвору з газогенератора у форкамеру до стінки форкамери для різних геометричних модифікацій вихідних отворів з газогенератора і розмірів форкамери в момент часу $\mathrm{t}=1$ мс.

Очевидно, що розмір форкамери не впливає на значення числа Маха і величину тиску на зрізі отворів з газогенератора, оскільки по довжині отворів течія стає надзвуковою, при цьому впливом примежового шару на стінках отворів можна знехтувати. Усередині форкамери струмінь продовжує прискорюватися навіть при куті $30^{\circ}$ дифузора отворів. Потім струмінь гальмується і на деякій відстані від стінки форкамери утворюється локальний прямий стрибок, що переходить у несиметричний косий стрибок. Розбіжність значень тиску у точці зупинки струменя при зміні параметрів отвору і форкамери не перевищує $40 \%$, але максимальне значення падіння тиску $\mathrm{P}_{\text {wall }} / \mathrm{P}_{\mathrm{gas}}=0.355$ реалізується при малому об'ємі форкамери $\left(\mathrm{V}_{\mathrm{f}}=0.039\right)$ при $\alpha=0^{\circ}$, в той час при більшому об'ємі форкамери $\left(\mathrm{V}_{\mathrm{f}}=0.084\right)-\mathrm{P}_{\text {wall }} / \mathrm{P}_{\text {gas }}=0.376$ при $\alpha=30^{\circ}$. 
XX Міжнародний симпозіум «Методи дискретних особливостей в задачах математичної фізики/Discrete Singularities Methods in Mathematical Physics»,

\section{МДОЗМФ/DSMMPh-2021}

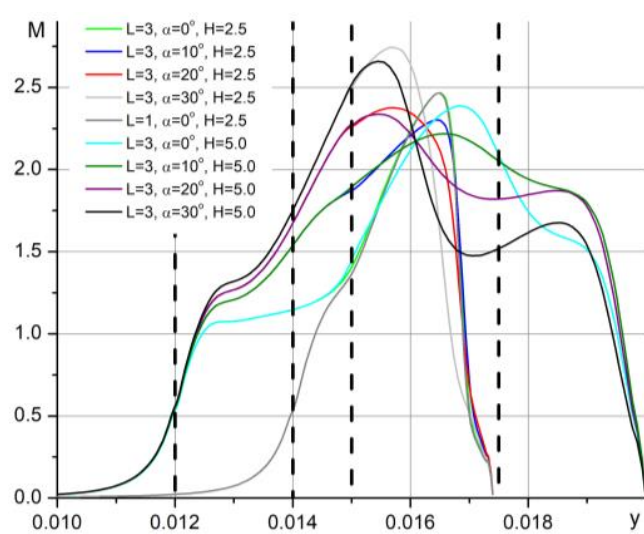

a)

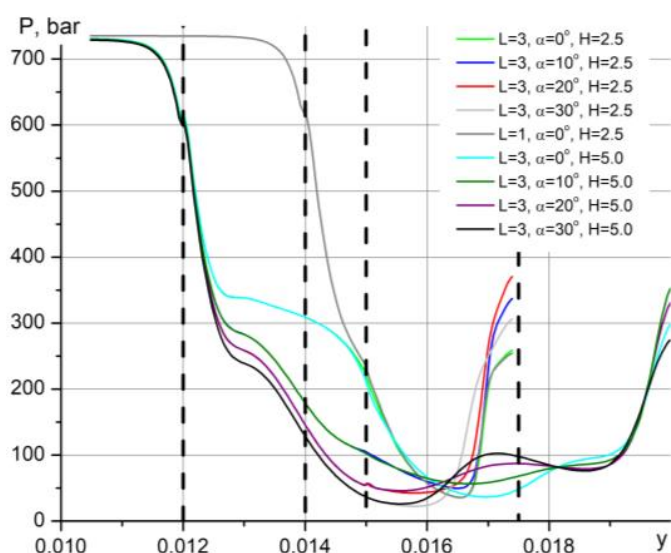

б)

Рис.3. Розподіли числа Маха (а) і тиску (б) вздовж осі циліндричного отвору.

Поля числа Маха в центральному перерізі форкамери для різних значень розглянутих параметрів наведено на Рис.4. Найбільші значення числа Маха сконцентровано в області первинного струменя, де $\mathrm{M}>2$, але й в області гальмування струменя після косих стрибків число Маха також приймає надзвукові значення (M>1), 3 якими потік прямує до кільцевого сопла. В районі вихідного кільцевого сопла структура поля тиску залишається відносно однорідною і мінімальне значення тиску в цій області дорівнює $\mathrm{P}_{\text {noz }} / \mathrm{P}_{\text {gas }}=0.075\left(\mathrm{~V}_{\mathrm{f}}=0.039\right)$ та $\mathrm{P}_{\text {noz }} / \mathrm{P}_{\mathrm{gas}}=0.089\left(\mathrm{~V}_{\mathrm{f}}=0.084\right)$ при $\alpha=0^{\circ}$.

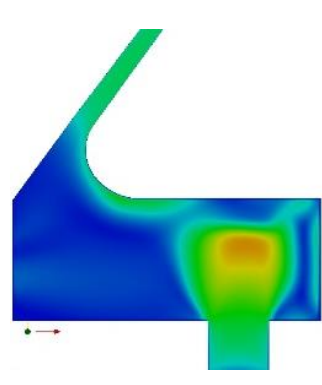

a)

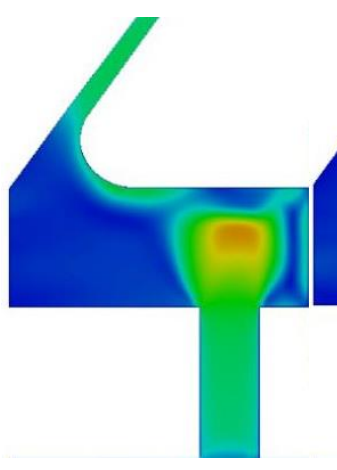

б)

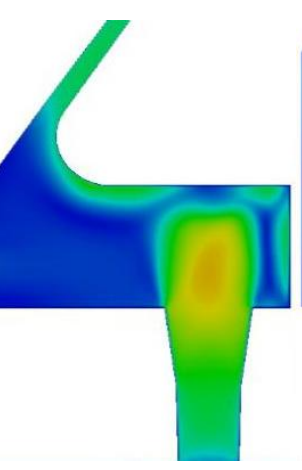

в)

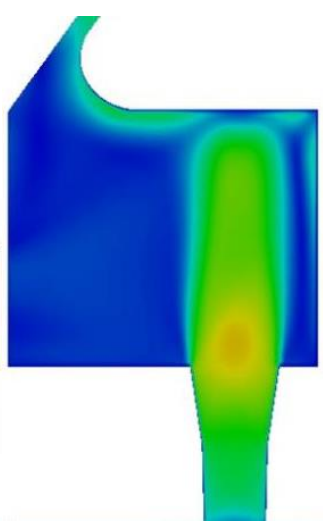

г)

Рис.4. Поля числа Маха в центральному перерізі форкамери : $\mathrm{L}=1$ мм, $\mathrm{H}=2.5$ мм, $\alpha=0^{\circ}$ (a); $\mathrm{L}=3$ мм, $\mathrm{H}=2.5$ мм, $\alpha=0^{\circ}, 20^{\circ}$ (б, в); $\mathrm{L}=3$ мм, $\mathrm{H}=5.0$ мм, $\alpha=20^{\circ}$ (г).

\section{4. Висновки}

Визначено параметри форкамери імпульсного надзвукового ежектора, що забезпечують стабільну роботу надзвукового кільцевого сопла при вхідному тиску $35 \div 45$ атм і масовій витраті ежектуючого газу $0.5 \div 0.6$ кг/с. 
Аналіз чисельних результатів показав, що максимальне дроселювання тиску газогенератора відбувається при менших значеннях відстані від отвору газогенератора до протилежної стінки форкамери (2.5 мм).

Точковий вихід газу з газогенератора в форкамеру формує нерівномірну картину течії у форкамері, але ступінь нерівномірності на вході до сопла ежектора досить низька, що дозволяе вважати граничні умови на вході до сопла ежектора незалежними від азимутальної координати, тобто моделювання течії в соплі та камері змішування ежектора можна виконувати в осесиметричній постановці.

\title{
ЛІТЕРАТУРА
}

1. Гуськов О.В, Копчёнов В.И., Липатов И.И., Острась В.Н., Старухин В.П. Процессы торможения сверхзвуковых течений в каналах. М.: Физматлит, 2008. $168 \mathrm{c}$.

2. Пензин В.И. Псевдоскачок и отрывное течение в прямоугольных каналах. Ученые записки ЦАГИ. 1988. Т.19, №1. С. 105-112.

3. Коробов В.И., Парамонов Ю.А., Загуменный Я.В. Течение в эжекторной системе с полуограниченной высокоскоростной струей. Прикладная гидромеханика. 2007. Том 9, № 1. С. 36-44.

4. Lee J.S., Jang G.Y., Kim S., Kim S.C. Dynamic PIV measurement of a compressible flow issuing from an airbag inflator nozzle. Journal of Thermal Science. 2006. V. 15, No. 4. P. 377-381.

5. Воропаев Г.А., Розумнюк Н.В., Загуменный Я.В., Сирош Е.А. Взаимодействие импульсной сверхзвуковой пристенной струи с дозвуковым потоком в ограниченном объеме. Збірник тез VI Міжнародної науково-практичної конференції «Комп'ютерна гідромеханіка», Київ, 2018, С. 16-18.

6. Bartkowski P. Numerical simulation of the air-bag inflation process. Machine Dynamics Research. 2016. V. 40, No 4. P. 121-130.

7. Bendjaballah D., Bouchoucha A., Sahli M.L., Gelin J.-C. Numerical modelling and experimental analysis of the passenger side airbag deployment in out-of-position. International Journal of Crashworthiness. 2017. V. 22, Is. 5. P. 527-540.

8. Абрамович Г.Н. Прикладная газовая динамика. М.: Наука, 1969. 824 с.

Надійшла 30.05.2021.

\section{Моделирование газодинамических процессов в элементах импульсного эжектора}

\author{
Г.О. Воропаєв, Я.В. Загуменний, Н.В. Розумнюк \\ Інститут гідромеханіки НАН України, Київ, Україна \\ e-mail: voropaiev.gena@gmail.com,zagumennyi@gmail.com
}

В работе представлены результаты численного моделирования газодинамических процессов в форкамере импульсной эжекторной системы, с целью определения ее оптимальных геометрических параметров для обеспечения максимального коэффициента эжекции. При сверхвысоком давлении ежектирующего газа (>100 атм) 
XX Міжнародний симпозіум «Методи дискретних особливостей в задачах математичної фізики/Discrete Singularities Methods in Mathematical Physics»,

\section{МДОЗМФ/DSMМPh-2021}

невозможно создать расчетное сопло с непрерывно изменяемой площадью сечения и ограниченной длиной, поэтому между источником высокого давления (газогенератором) и соплом эжектора необходимо разместить форкамеру для дросселирования полного давления газогенератора. С целью оптимизации параметров форкамеры эжектора с дискретными соплами газогенератора и рабочим давлением в диапазоне $400 \div 1000$ атм была проведена серия расчетов, которые позволили определить параметры форкамеры, обеспечивающие стабильную работу сверхзвукового кольцевого сопла при входном давлении $35 \div 45$ атм и массовом расходе ежектирующего газа $0.5 \div 0.6$ кг/с. Трехмерное численное моделирование точечного истечения газа из газогенератора в форкамеру и дальше в кольцевое сопло показало, что степень неравномерности картины течения в форкамере на входе в сопло эжектора является достаточно низкой, что обосновывает проведение численного моделирования течения в сверхзвуковом кольцевом сопли и камере смешивания эжектора в осесимметричной постановке и позволяет ограничить количество цилиндрических отверстий газогенератора без внесения существенной неоднородности в распределения характеристик по азимутальной координате.

Ключевые слова: эжектор, сверхзвуковая струя массовый расход, численное моделирование. 